\title{
Article \\ Methotrexate Neurotoxicity Is Related to Epigenetic Modification of the Myelination Process
}

\author{
Yu-Chieh Chen ${ }^{1,2}$ * , Jiunn-Ming Sheen ${ }^{1,2}$, Su-Chen Wang ${ }^{1}$, Mei-Hsin Hsu ${ }^{1}$, Chih-Cheng Hsiao ${ }^{1,2}$, \\ Kow-Aung Chang ${ }^{3}$ and Li-Tung Huang ${ }^{1, * \text { (D) }}$
}

1 Department of Pediatrics, Kaohsiung Chang Gung Memorial Hospital and Chang Gung University College of Medicine, Kaohsiung 833, Taiwan; ray.sheen@gmail.com (J.-M.S.); cuzhengwang@gmail.com (S.-C.W.); a03peggy@cgmh.org.tw (M.-H.H.); chihcheng.hsiao@gmail.com (C.-C.H.)

2 Department of Traditional Medicine, Chang Gung University, Guishan, Taoyuan 333, Taiwan

3 Department of Anesthesiology, Kaohsiung Chang Gung Memorial Hospital and Chang Gung University College of Medicine, Kaohsiung 833, Taiwan; kowaung@adm.cgmh.org.tw

* Correspondence: gesicht27@gmail.com (Y.-C.C.); litung.huang@gmail.com (L.-T.H.); Tel.: +886-975056730 (Y.-C.C. \& L.-T.H.)

Citation: Chen, Y.-C.; Sheen, J.-M.; Wang, S.-C.; Hsu, M.-H.; Hsiao, C.-C.; Chang, K.-A.; Huang, L.-T.

Methotrexate Neurotoxicity Is Related to Epigenetic Modification of the Myelination Process. Int. J. Mol. Sci. 2021, 22, 6718. https://doi.org/ $10.3390 /$ ijms 22136718

Academic Editor: Hideko Sone

Received: 22 May 2021

Accepted: 17 June 2021

Published: 23 June 2021

Publisher's Note: MDPI stays neutral with regard to jurisdictional claims in published maps and institutional affiliations.

Copyright: (c) 2021 by the authors. Licensee MDPI, Basel, Switzerland. This article is an open access article distributed under the terms and conditions of the Creative Commons Attribution (CC BY) license (https:// creativecommons.org/licenses/by/ $4.0 /)$.

\begin{abstract}
With the improvement of the survival rate of acute lymphoblastic leukemia (ALL) in children, some children ALL survivors reveal inferior intellectual and cognition outcome. Methotrexate (MTX), while serving as an essential component in ALL treatment, has been reported to be related to various neurologic sequelae. Using combined intrathecal (IT) and intraperitoneal (IP) MTX model, we had demonstrated impaired spatial memory function in developing rats, which can be rescued by melatonin treatment. To elucidate the impact of MTX treatment on the epigenetic modifications of the myelination process, we examined the change of neurotrophin and myelination-related transcriptomes in the present study and found combined IT and IP MTX treatment resulted in altered epigenetic modification on the myelination process, mainly in the hippocampus. Further, melatonin can restore the MTX effect through alterations of the epigenetic pathways.
\end{abstract}

Keywords: methotrexate; neurotrophin; myelination; epigenetic

\section{Introduction}

Cognitive impairment is commonly reported in patients with cancer treated with chemotherapy [1,2]. With improvements in diagnostic and therapeutic strategies, the long-term survival rate of pediatric acute lymphoblastic leukemia (ALL) patients is almost 90\% [3-5]. However, follow-up studies on childhood leukemia survivors revealed impaired intellectual and cognitive functions [6-8], which raised interest in the study of the neurologic impact of chemotherapy medications on pediatric cancer survivors.

Methotrexate (MTX), a folate analog, administered intravenously or by intrathecal (IT) infusion, has been used for more than 60 years for cancer treatment, particularly in ALL [9]. However, clinical studies have shown that MTX chemotherapy is responsible for both functional and morphological changes in the brain, and it can result in serious late neurologic sequelae, notably cognitive impairment [10-12]. Most preclinical studies have focused on MTX treatment in adult rodents, but rarely in adolescent rodents. Recently, Wen et al. used models combining intraperitoneal (IP) and IT MTX protocols, which mimicked ALL treatment protocols, and found impaired memory, neuroinflammation, and impaired neurogenesis in developing rats [13]. Recently, we used developing rats treated with IP, IT, or combined IT and IP MTX intended to mimic the treatment model in acute lymphoblastic leukemia in children and found that combined IP and IT MTX treatment caused spatial deficits in developing rats [14]. For better understanding of the underlying mechanism interplay between brain neurotrophin and myelination-related transcriptomes and brain functional impairment, we focus on the myelination process change in response to MTX treatment in this study. 
MTX, a commonly used antimetabolite chemotherapeutic agent, is associated with chemotherapy-related cognitive impairment, colloquially known as "chemobrain" or "chemofog" [15-17]. Gibson et al. demonstrated that tri-glial dysfunction underlies MTX chemotherapy-related cognitive impairment (CRCI), with direct effects of MTX on microglial activation, subsequently inducing neurotoxic astrocyte reactivity and oligodendroglial lineage dysregulation [18]. Microglial depletion following MTX exposure decreases astrocyte reactivity, normalizes oligodendroglial lineage dynamics and myelination, and rescues cognitive function in a mouse model of juvenile MTX exposure [18]. In our previous study, we found that combined IT and IP MTX treatment resulted in myelin loss; this was evidenced by a decrease in myelin-related protein expression and a decrease in the expression of protein arginine $\mathrm{N}$-methyltransferase 1(PRMT 1), which was considered to be related to the myelination process [14]. Therefore, we presumed that MTX-related cognitive impairment is mediated through myelin loss by directly exerting its effect on the myelination process or through the epigenetic regulation process. Therefore, we tested the effect of MTX treatment on the myelination process in developing rats, mainly focusing on the epigenetic regulation of BDNF and myelination-related transcriptomes in this study.

Recently, there have been increasing studies on melatonin for the elimination of various MTX toxicities, including mucositis, enterocolitis, and renal damage [19-21]. However, studies utilizing melatonin to reverse MTX neurotoxicity are lacking. We established an MTX-treated animal model mimicking the pediatric leukemia treatment protocol and tested whether MTX treatment (either through intravenous or intrathecal route) would result in neurologic deficits. Moreover, we tested the therapeutic effects of melatonin on MTXinduced neurotoxicity. Our study revealed that melatonin rescued the MTX-related spatial memory defects, based on the outcomes of the Morris water maze test [14]. Previously, melatonin was reported to rescue MTX neurotoxicity through its role as an oxidative stress scavenger. In this study, we further explored the effect of melatonin treatment on the epigenetic modification of MTX neurotoxicity.

Several epigenetic mechanisms appear to be related to nervous system development. Emerging evidence has revealed that neurogenesis is associated with unique epigenetic features. From the embryonic stage to the adjustment stage, several proteins, including glial fibrillary acidic protein, brain-derived neurotrophic factor (BDNF), and Na-K-Clcotransporter 1, participate in neurogenesis. Furthermore, recent studies have shown that impaired epigenetic modification of the gene expression of neurogenetic proteins is related to the pathogenesis of several neurological disorders and the neurotoxicity of various medications. Although epigenetic mechanisms have been implicated in mediating high levels of plasticity during early development, the decreased plasticity and sensitivity that occurs later can also be viewed from an epigenetic perspective. During the onset of critical period plasticity, oligodendrocytes start to express specific myelin structural proteins, including myelin basic protein (MBP), myelin-associated glycoprotein, myelin oligodendrocyte glycoprotein, and myelin-associated oligodendrocyte basic protein. The manipulation of the epigenetic status of oligodendrocytes may also be an effective strategy for modulating plasticity. Sry-related HMg-box (SOX) genes are transcription factors involved in the developmental specification and are classified into nine groups based on sequence similarity and function [22]. Among them, the SOXE group, composed of SOX8, SOX9, and SOX10, is involved in the specification of myelinating glial cells [23]. SOX10 is considered the main SOX transcription factor that regulates oligodendrocyte specification and maturation, as well as epigenetic functions [24]. As growing evidence has revealed the role of SOX10 in the myelination process, especially the aggravation of myelin maturation $[25,26]$, we used SOX10 in this study as a marker to determine the effect of MTX treatment on its expression and epigenetic modification. Besides, in order to evaluate the impact of MTX treatment on the developing brain, we examined the effect of MTX treatment on the epigenetic modifications of myelination-related transcriptomes, including MBP and SOX 10, in a developing rat model. 
BDNF is a member of the neurotrophin family of growth factors related to the canonical nerve growth factor. In several brain ischemia/reperfusion models, BDNF is related to neurogenesis and repair $[27,28]$. Recent studies have demonstrated that BDNF not only potentiates normal central nervous system myelination during development but also enhances recovery after myelin injury [29]. Moreover, $\mathrm{Ng}$ et al. found that the serum BDNF concentrations are related to self-perceived cognitive impairment after chemotherapy [30]. Azoulay et al. found that BDNF protein concentrations and gene polymorphisms may be predictors of peripheral neuropathy after chemotherapy [31]. Furthermore, Geraghty et al. found that loss of adaptive myelination contributes to MTX-related cognitive impairment and may be rescued by the manipulation of BDNF expression [32]. In conclusion, the above studies found that MTX decreased cortical BDNF expression, which was restored by microglial depletion. In this study, we tested the degree of BDNF promoter and BDNF mRNA expressions in MTX-treated developing rats. In addition, BDNF promoter methylation status after MTX treatment was examined to evaluate the epigenetic modification of BDNF after MTX treatment, which provides a comprehensive evaluation of the epigenetic modification of the genes involved in the brain myelination process after MTX treatment in the developing brain of developing rats.

Protein arginine methylation, a post-translational modification recognized as important as phosphorylation or ubiquitination, is catalyzed by nine members of the protein arginine methyltransferase family (PRMT1-9) [33]. Most PRMT family members, including PRMT 1, 2, 3, 5, 7, and 8 and coactivator-associated arginine methyltransferase 1 (CARM1, also known as PRMT4), were confirmed to be expressed in the mouse brain. However, compared with other PRMTs, the expression of PRMT1 is observed at earlier stages of development, which implies its importance in stem cell biology and development. In addition, brain cell RNA-seq studies have demonstrated PRMT1 expression in all major central nervous system (CNS) cell types, including neurons, astrocytes, oligodendrocytes, and microglia $[33,34]$. Recent reports have revealed the significance of PRMT1 in the development of neurons, astrocytes, and oligodendrocytes, although further investigations, particularly of proliferation, differentiation, and development, are needed. Furthermore, several reports have suggested the involvement of PRMT1 in various CNS diseases, including neurodegenerative disorders, brain tumors, and multiple sclerosis $[33,34]$. These findings suggest that PRMT1 regulates the development and physiological functions of the brain.

Recently, Forster et al. found that altered methylation may potentially act as a mediating mechanism between MTX treatment and subsequent neurotoxicities [35]. Our previous studies have demonstrated that MTX treatment can alter the myelination process, which is presumed to be due to increased oxidative stress. We have found alterations in PRMT1 expression in a previous study, and growing evidence suggests that PRMT1 plays an essential role in post-translational modification through interaction with myelination-related transcriptomes, which implies that an epigenetic mechanism underlies MTX neurotoxicity. However, the PRMT responsible for the methylation of the identified proteins in vivo and the proteins that are real targets of PRMT1 in the brain have not been established. Therefore, in combination with these substrate-enrichment methodologies, we evaluated the role of PRMT1 in the post-translational modification of myelination-related transcriptomes.

\section{Results}

\subsection{Methotrexate Treatment Resulted in Altered Myelination-Related Protein mRNA Expression}

As shown in Figure 1a, the quantifications of BDNF exon IV, MBP, and SOX10 mRNA expression in the cortex via real-time PCR revealed that MTX treatment resulted in significant downregulation of MBP and SOX 10 mRNA expression in brain cortex while BDNF exon IV was declined but not significatly changed $(\mathrm{F}(2,15)=5.666, p=0.015$; $\mathrm{F}(2,15)=9.881, p=0.002 ; \mathrm{F}(2,15)=2.515, p=0.114$, respectively). However, melatonin did not restore the BDNF exon IV mRNA levels, whereas recovery effects were noted in MBP and SOX mRNA expressions. These findings imply that MTX treatment disturbed 
BDNF, MBP, and SOX10 mRNA expressions, but melatonin rescued only the myelination function and not cognition in the cortex. In the hippocampus, a similar phenomenon was observed. As shown in Figure 1b, MTX treatment resulted in significant downregulation of BDNF exon IV and SOX10 mRNA expressions while MBP slightly decreased without significance $(\mathrm{F}(2,18)=10.401, p=0.001 ; \mathrm{F}(2,18)=5.102, p=0.018 ; \mathrm{F}(2,18)=1.099$, $p=0.354$, respectively). However, melatonin did not restore the BDNF exon IV, MBP, and SOX10 mRNA levels. These results suggest that MTX treatment disturbed myelination and cognitive functions in the hippocampus.
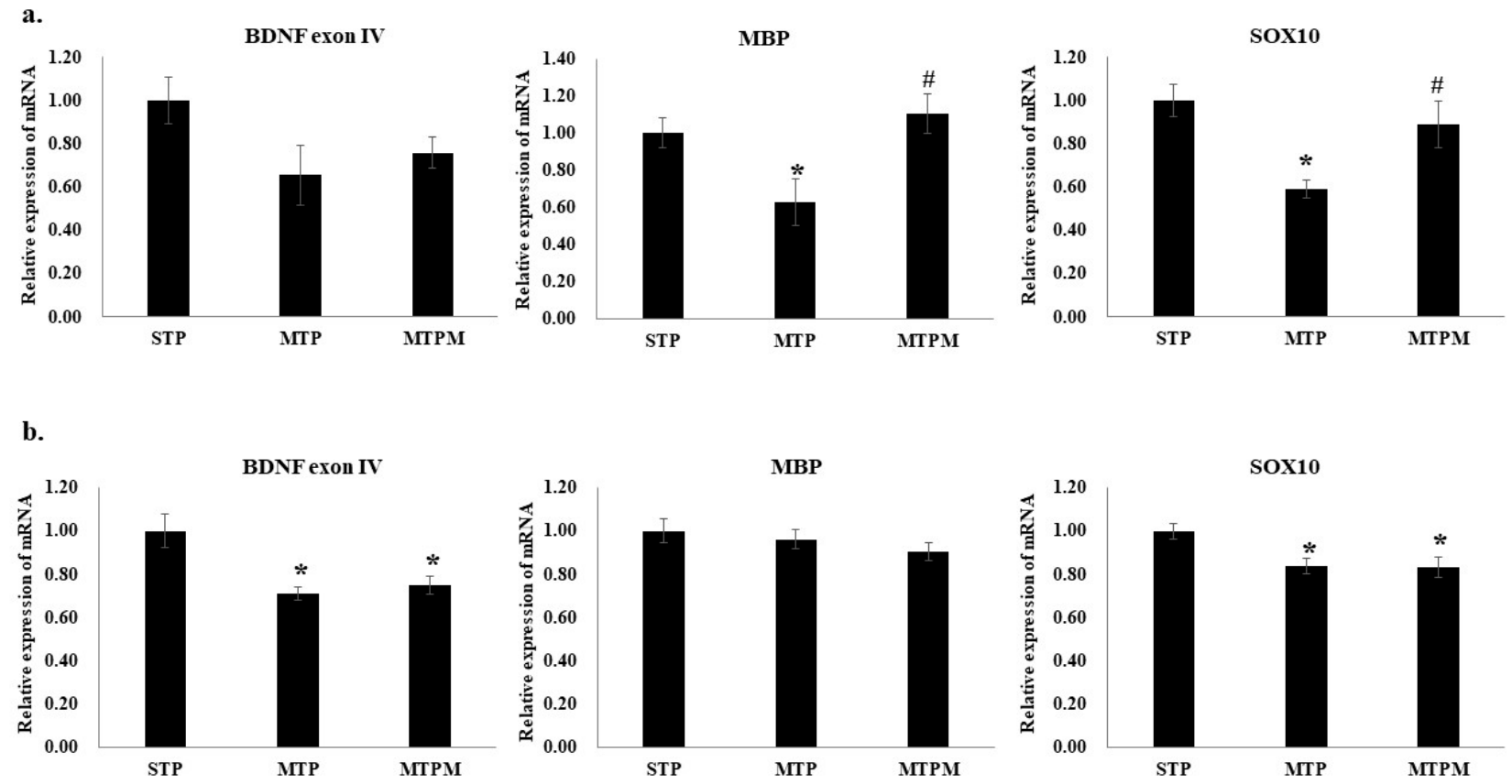

Figure 1. Methotrexate treatment resulted in myelination-related protein mRNA expression alteration; however, melatonin recovery effects were significantly observed in cortex but not hippocampus. (a) MTX treatemnt resulted in significant down-regulation of MBP and SOX 10 mRNA expressions in brain cortex while BDNF exon IV was declined but not significatly changed. (b) MTX treatemnt resulted in a significant down-regulation of BDNF exon IV and SOX10 mRNA expression while MBP slightly decreased without significance in the hippoccampus (*: $p<0.05$ vs. STP; \#: $p<0.05$ vs. MTP).

2.2. Combined Intrathecal and Intraperitoneal Methotrexate Treatment Resulted in an Altered $C p G$ Methylation Status of the BDNF Exon IV Promoter in Both the Brain Cortex and Hippocampus

As shown in Figure 2, pyrosequencing examination of the cortex revealed increased methylation of $\mathrm{CpG}$ at positions 5, 6, 7, and 8 (Pos5: F $(2,18)=3.780, p=0.043$; Pos6: $\mathrm{F}(2,18)=8.377, p=0.003$; Pos7: F $(2,18)=4.469, p=0.027$; Pos8: F $(2,18)=3.689$, $p=0.045$, Figure $2 \mathrm{~b})$. In the hippocampus, increased methylation of the $\mathrm{CpG}$ at positions 1-8 was noted (Pos1: F $(2,18)=4.846, p=0.021 ;$ Pos2: F $(2,18)=7.500, p=0.004 ;$ Pos3: $\mathrm{F}(2,18)=4.139, p=0.033$; Pos4: $\mathrm{F}(2,18)=5.880, p=0.011$; Pos5: $\mathrm{F}(2,18)=6.091, p=0.010$; Pos6: F $(2,18)=6.091, p=0.010$; Pos7: F $(2,18)=5.850, p=0.011$; Pos8: F $(2,18)=5.418$, $p=0.014$; respectively, Figure 2c). However, the degree of methylation status alteration in response to melatonin treatment varied in the brain cortex and hippocampus (Figure $2 b, c)$. 


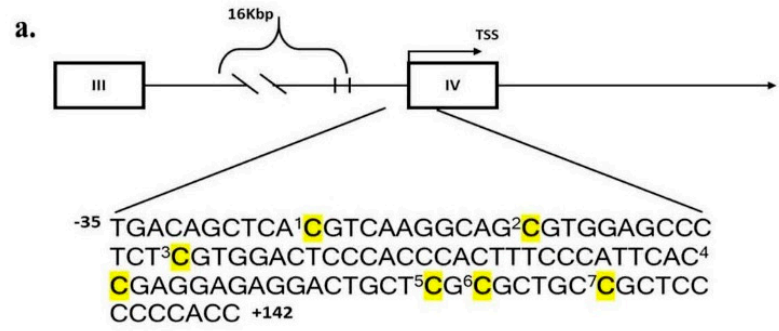

b.

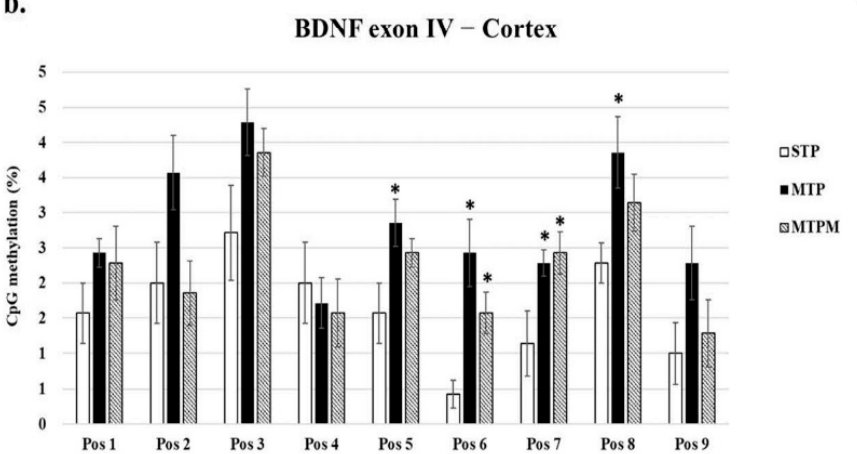

c.

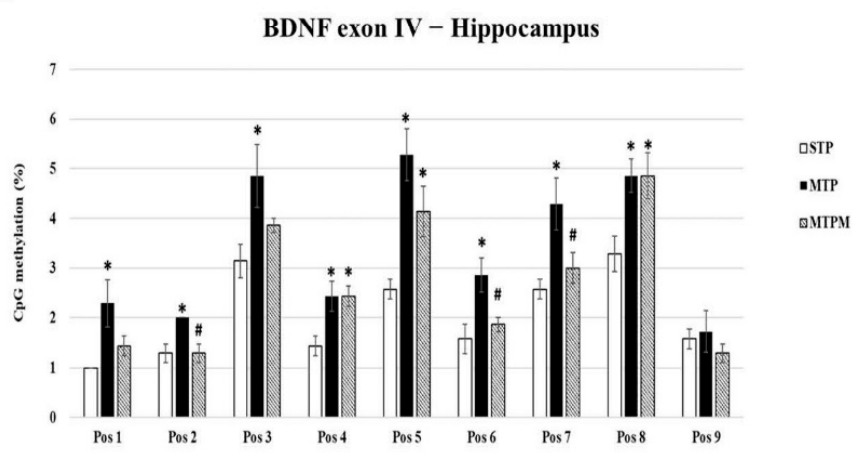

Figure 2. MTX treatment stimulated the alteration of CpG methylation status in BDNF exon IV promoter while melatonin attenuated the alteration resulted from MTX. (a) Scheme of BDNF exon IV promoter region for pyrosequencing. CpG positions are highlighted in yellow background. (b) Methylation status in different CpG sites of BDNF exon IV promoter in brain cortex. (c) Methylation status in different CpG sites of BDNF exon IV promoter in hippocampus $\left({ }^{*} p<0.05 \mathrm{vs}\right.$. STP; \# $p<0.05$ vs. MTP). "C" highlights in bold with yellow background indicate variable CpG positions.

2.3. Combined Intrathecal and Intraperitoneal Methotrexate Treatment Resulted in Altered CpG Methylation Status of the SOX10 and MBP Promoter in Both Brain Cortex and Hippocampus

As shown in Figure 3, the CPG methylation status of the SOX10 promoter in the brain cortex examined by pyrosequencing revealed an increased methylation of $\mathrm{CpG}$ at positions $1,2,5,6,8$, and 9 (Pos 1: F $(2,18)=14.546, p=0.000 ; \operatorname{Pos} 2: \mathrm{F}(2,18)=5.425, p=0.014 ;$ Pos 5: F $(2,18)=8.231, p=0.003 ; \operatorname{Pos} 6: \mathrm{F}(2,18)=6.394, p=0.008 ; \operatorname{Pos} 8: \mathrm{F}(2,18)=7.952, p=0.003$; Pos 9: $\mathrm{F}(2,18)=5.891, p=0.011)$ after MTX treatment (Figure 3b). In the hippocampus, the upregulation of $\mathrm{CpG}$ methylation was significantly observed at positions 1-9 (Pos 1: $\mathrm{F}(2,18)=61.174, p=0.000 ; \operatorname{Pos} 2: \mathrm{F}(2,18)=9.265, p=0.002 ; \operatorname{Pos} 3: \mathrm{F}(2,18)=4.651$, $p=0.024 ;$ Pos 4: F $(2,18)=4.615, p=0.024 ;$ Pos $5: \mathrm{F}(2,18)=3.933, p=0.038$; Pos $6: \mathrm{F}(2,18)=6.831, p=0.006 ; \operatorname{Pos} 7: \mathrm{F}(2,18)=6.844, p=0.006 ; \operatorname{Pos} 8: \mathrm{F}(2,18)=8.759, p=0.002$; Pos 9: $\mathrm{F}(2,18)=10.233, p=0.001$ ) in the MTP groups (Figure 3c). For MBP, the upregulation of the CpG methylation status at positions 2, 3, 4, and $5(\operatorname{Pos} 2: \mathrm{F}(2,18)=8.237, p=0.003$; Pos 3: $\mathrm{F}(2,18)=8.437, p=0.003 ; \operatorname{Pos} 4: \mathrm{F}(2,18)=5.996, p=0.010 ; \operatorname{Pos} 5: \mathrm{F}(2,18)=3.848$, $p=0.041)$ in the brain cortex and the upregulation of the CpG methylation status at positions 1, 2, 3, 5, 6, and $7(\operatorname{Pos} 1: \mathrm{F}(2,18)=6.786, p=0.006 ; \operatorname{Pos} 2: \mathrm{F}(2,18)=6.454, p=0.008$; Pos 3: F $(2,18)=7.152, p=0.005 ;$ Pos 5: F $(2,18)=7.651, p=0.004 ;$ Pos 6: F $(2,18)=13.078$, $p=0.000 ;$ Pos 7: F $(2,18)=14.299, p=0.000)$ in the hippocampus were noted (Figure 3e,f). Similar to its effect on BDNF methylation status, melatonin treatment resulted in a varied response of methylation status changes in the SOX10 and MBP promoters. Taken together, these findings suggest that the hippocampus is more susceptible to MTX treatment than the brain cortex in relation to changes in methylation status. 


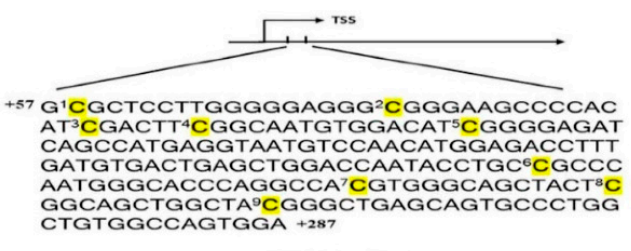

b.

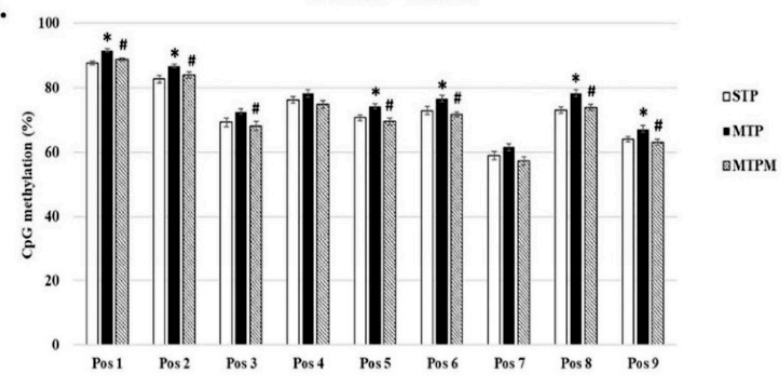

c.

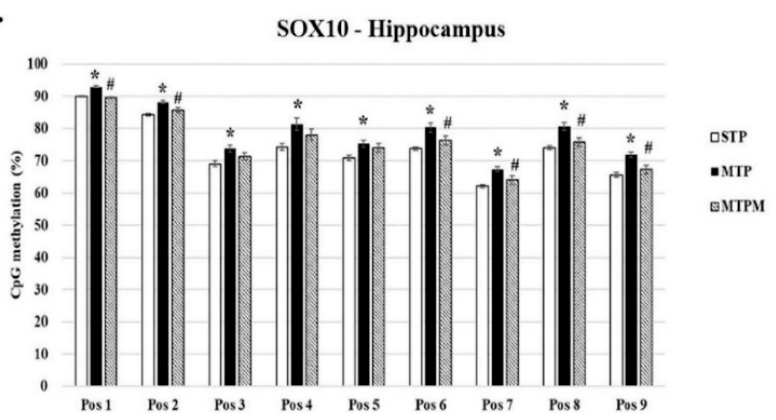

d.

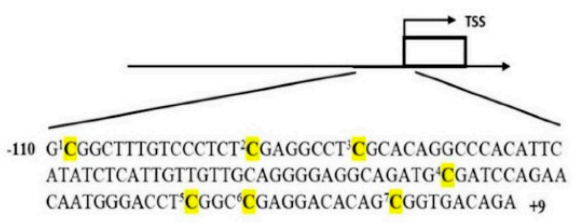

MBP - Cortex

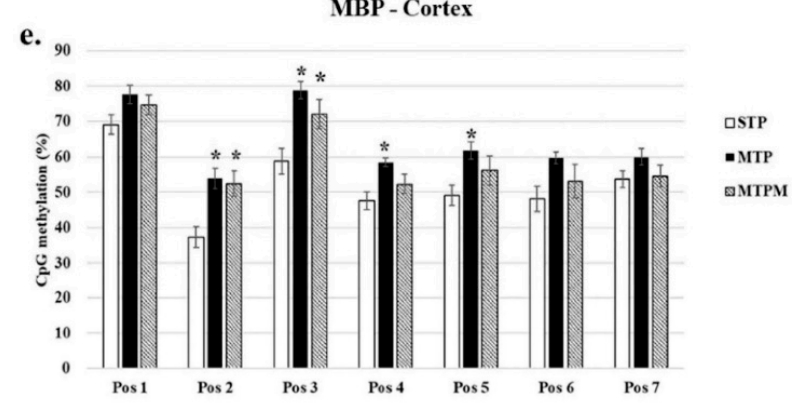

f.

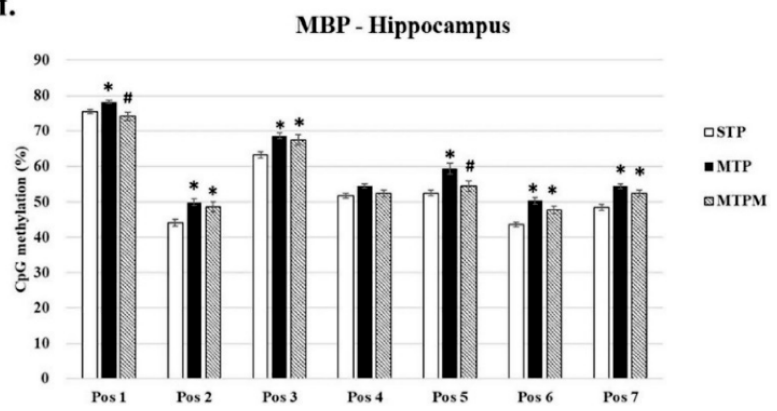

Figure 3. MTX treatment stimulated the alteration of $\mathrm{CpG}$ methylation status in myelination-related genes promoter, while melatonin attenuated the alteration resulted from MTX. (a) Scheme of SOX10 promoter region for pyrosequencing. CpG positions are highlighted in yellow background. (b) Methylation status in different CpG sites of SOX10 promoter in brain cortex. (c) Methylation status in different CpG sites of SOX10 promoter in hippocampus. (d) Scheme of MBP promoter region for pyrosequencing. $\mathrm{CpG}$ positions are highlighted in yellow background. (e) Methylation status in different $\mathrm{CpG}$ sites of MBP promoter in brain cortex. (f) Methylation status in different CpG sites of MBP promoter in hippocampus. " $\mathrm{C}$ " highlights in bold with yellow background indicate variable CpG positions. (*: $p<0.05$ vs. STP; \#: $p<0.05$ vs. MTP).

2.4. Combined Intrathecal and Intraperitoneal Methotrexate Treatment Resulted in Epigenetic Modification of BDNF Exon IV Promoter, Myelin Basic Protein (MBP) and SOX 10 Promoter

As shown in Figure 4, ChIP was carried out with anti-histone H4 dimethyl arg3 asymmetric (H4R3me2a), anti-methyl-CpG binding protein 2 (MeCP2), anti-histone H3 trimethyl lysine 36 (H3K36me3), and anti-histone $\mathrm{H} 3$ trimethyl lysine 4 (H3K4me3). In brain cortex, while statistically insignificant, decrease in the level of H4R3me2a and increase in the level of MeCP2 were noted after MTX treatment (H4R3me2a: F $(2,9)=6.561$, $p=0.017$; H3K4me3: F $(2,9)=0.828, p=0.468 ; \mathrm{MeCP} 2: \mathrm{F}(2,9)=2.271, p=0.159$; H3K36me3: F $(2,9)=3.366, p=0.081$ ) (Figure 4a). In hippocampus, significant decrease in the level of H4R3me2a and increase in the level of MeCP2 were noted after MTX treatment $(H 4 R 3 m e 2 a: F(2,9)=6.298, p=0.019 ; \operatorname{MeCP} 2: \mathrm{F}(2,9)=6.452, p=0.018$; H3K36me3: F $(2,9)=2.332, p=0.153$; H3K4me3: $F(2,9)=0.661, p=0.540$, Figure $4 b)$. Interestingly, melatonin treatment successfully rescued the MTX effect on the alteration of the level of H4R3me2a in both brain cortex and hippocampus $(F(2,9)=2.271, p=0.0159$; H4R3me2a: F $(2,9)=6.298$, respectively, Figure 4a,b). 


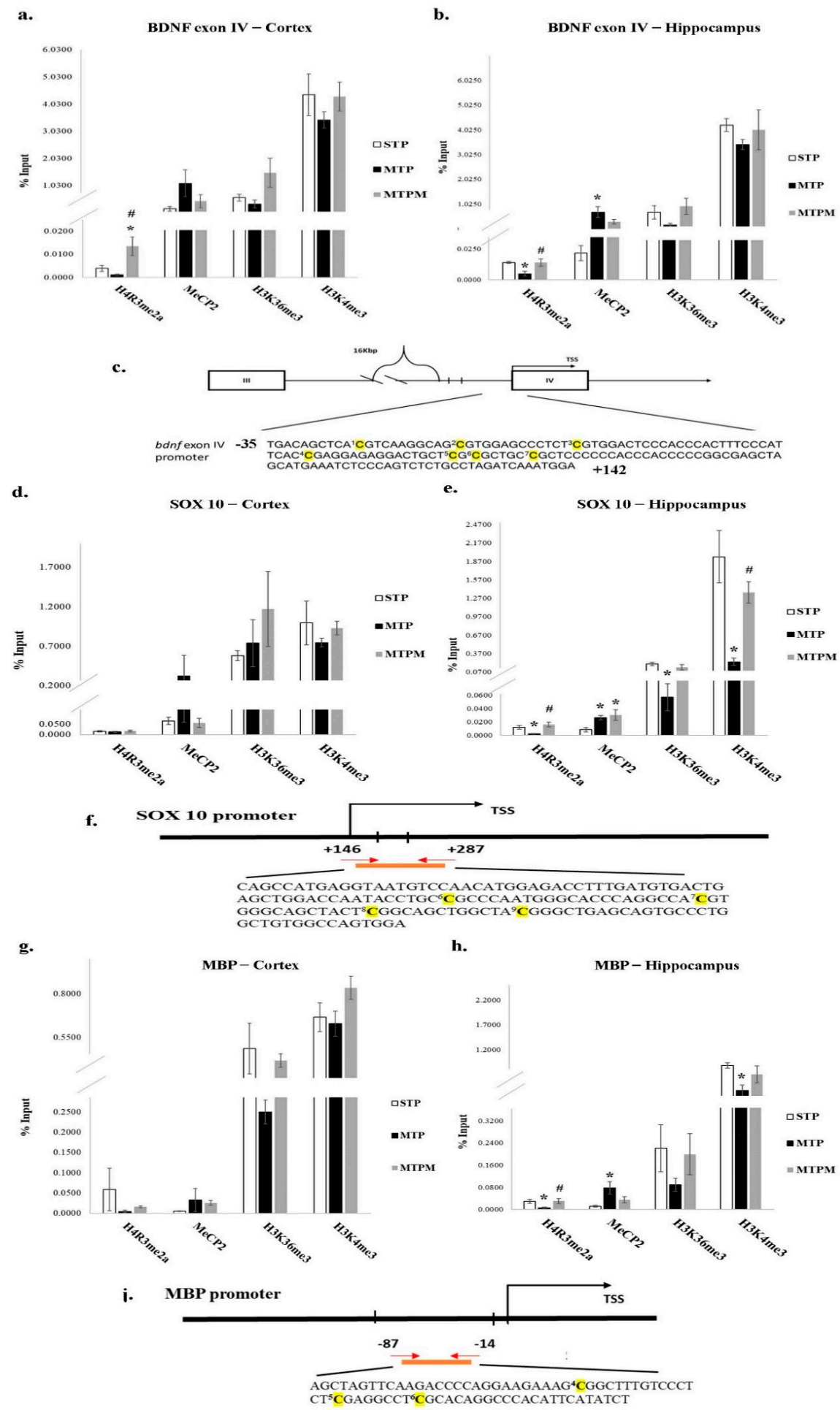

Figure 4. MTX treatment altered epigenetic modification of BDNF exon IV and myelination-related gene promoter, however, melatonin prevented the alteration induced by MTX. (a) ChIP exam for BDNF exon IV promoter revealed decrease in the level of H4R3me2a and increase in the level of MeCP2 inbrain cortex. (b) ChIP exam for BDNF exon IV revealed significant decrease in the level of H4R3me2a and increase in the level of MeCP2 in the hippocampus and in the brain cortex, respectively. (c) BDNF IV promoter sequences for ChIP assay. (d) ChIP exam for SOX 10 promoter found less significant effect of MTX in brain cortex. (e) ChIP exam for SOX10 promoter found significant change in the levels of H4R3me2a, MeCP2, H3K36me3, and H3K4me3 in the hippocampus. (f) SOX10 promoter sequences for ChIP assay. (g) ChIP exam for MBP promoter decrease in the level of H4R3me2a and increase in the level of MeCP2 in brain cortex; (h) ChIP exam for MBP promoter revealed significant alteration of the expression levels in hippocampus. (i) MBP promoter sequences for ChIP assay. "C" highlights in bold with yellow background indicate variable CpG positions. (*: $p<0.05$ vs. STP; \#: $p<0.05$ vs. MTP). 
As for myelination related proteins, significant alteration of the levels of H4R3me2a, MeCP2, H3K36me3, and H3K4me3 of SOX10 promoter was noted after MTX treatment in the hippocampus (H4R3me2a: F $(2,9)=7.334, p=0.013$; MeCP2: F $(2,9)=4.808$ $p=0.038$; H3K36me3 F $(2,9)=4.644, p=0.041$, H3K4me3 F $(2,9)=10.601, p=0.004)$ while the effect of MTX on brain cortex was less significant (H4R3me2a: F $(2,9)=0.447$, $p=0.653$; H3K4me3: F $(2,9)=0.567, p=0.586 ; \mathrm{MeCP} 2$ : F $(2,9)=0.984, p=0.411$; H3K36me3: $F(2,9)=0.886, p=0.445$, Figure $4 d$,e). In addition, study on the levels of H4R3me2a, MeCP2, H3K36me3, and H3K4me3 of MBP promoter region revealed significant alteration of the expression levels in hippocampus (H4R3me2a: F $(2,9)=4.331$, $p=0.048$; H3K4me3: F $(2,9)=4.486, p=0.044 ; \mathrm{MeCP} 2: \mathrm{F}(2,9)=5.515, p=0.027$; H3K36me3: $\mathrm{F}(2,9)=1.126, p=0.366)$ compared with brain cortex (H4R3me2a: $\mathrm{F}(2,9)=0.895$, $p=0.442 ;$ H3K4me3: F $(2,9)=2.209, p=0.166 ; \mathrm{MeCP} 2: \mathrm{F}(2,9)=0.738, p=0.505$; H3K36me3: F $(2,9)=1.847, p=0.213$ ). (Figure $4 \mathrm{~g}, \mathrm{~h}$ ). Following melatonin treatment, H4R3me2a level seemed to recover both in SOX 10 and MBP promoter region in hippocampus (SOX10 in cotrex: $\mathrm{F}(2,9)=0.447, p=0.653$, hippocampus: $\mathrm{F}(2,9)=7.334$, $p=0.013$; MBP in cortex: $\mathrm{F}(2,9)=0.895, p=0.442$, hippocampus: $\mathrm{F}(2,9)=4.331, p=0.048$, Figure 4e,h). The above results suggested that MTX treatment modulated MBP and SOX10 expression through alteration of $\mathrm{H} 4 \mathrm{R} 3 \mathrm{me} 2 \mathrm{a}$ and $\mathrm{MeCP} 2$-binding affinity of promoter regions in hippocampus. Besides, H4R3me2a, a genes activator which catalyzes asymmetric dimethylation of H4R3 by protein arginine methyltransferase 1 (PRMT1), was found to moderately decrease in the promoter region 2 after MTX treatment, which implied that the epigenetic modifications after MTX treaetment may be induced by the alterations of the methyltransferase activities. Further, melatonin seemed to exert its effect on the epigenetic modification through H4R3me2a in the myelination proteins, mostly in the hippocampus.

2.5. PRMT1 Is Involved in the Post-Translational Modification of BDNF and Myelination-Related Transcriptomes in MTX-Treated Developing Rats

As shown in Figure 5, immunofluorescence staining of PRMT1 and BDNF in the cornu ammonis 1 (CA1) area of the hippocampal CA1 area revealed colocalization of PRMT1 and BDNF in the sham groups. After MTX treatment, decreased staining of both PRMT1 and BDNF was noted, which recovered after melatonin treatment and could be colocalized (Figure 5a). Since the present study focused mostly on the developing brain, we further checked PRMT1 expression by immunofluorescence-staining changes in early stage oligodendrocyte progenitor cells, which are O4 cells, after MTX treatment. We found decreased PRMT1 expression in O4 cells after MTX treatment, which could be rescued by melatonin treatment (Figure 5b). The above results indicated that PRMT1 was involved in the myelination of the developing brain and suggested that melatonin rescued the MTX effect by serving a role other than oxidant scavenging.

To further investigate the role of the post-translational modification of the myelinationrelated transcriptomes by PRMT1, we used the RIP method to study the interaction between PRMT1 and the RNA molecules of BDNF exon IV, MBP, and SOX10 (Figure 6). A significant decrease in the BDNF exon IV was found in both the brain cortex and hippocampus (cortex: F $(2,9)=23.466, p=0.000$; hippocampus: F $(2,9)=5.182, p=0.032$ ), which could be successfully rescued by melatonin (Figure 6). The expression levels of MBP and SOX10 in the hippocampus were significantly decreased (MBP: F $(2,9)=4.947, p=0.036$; SOX10: $\mathrm{F}(2,9)=6.125, p=0.021$, Figure $6 \mathrm{~b})$. In summary, the above findings suggest that PRMT1 plays an essential role in the post-translational modification of BDNF, MBP, and SOX10, while the hippocampus was more strongly affected by MTX treatment. 


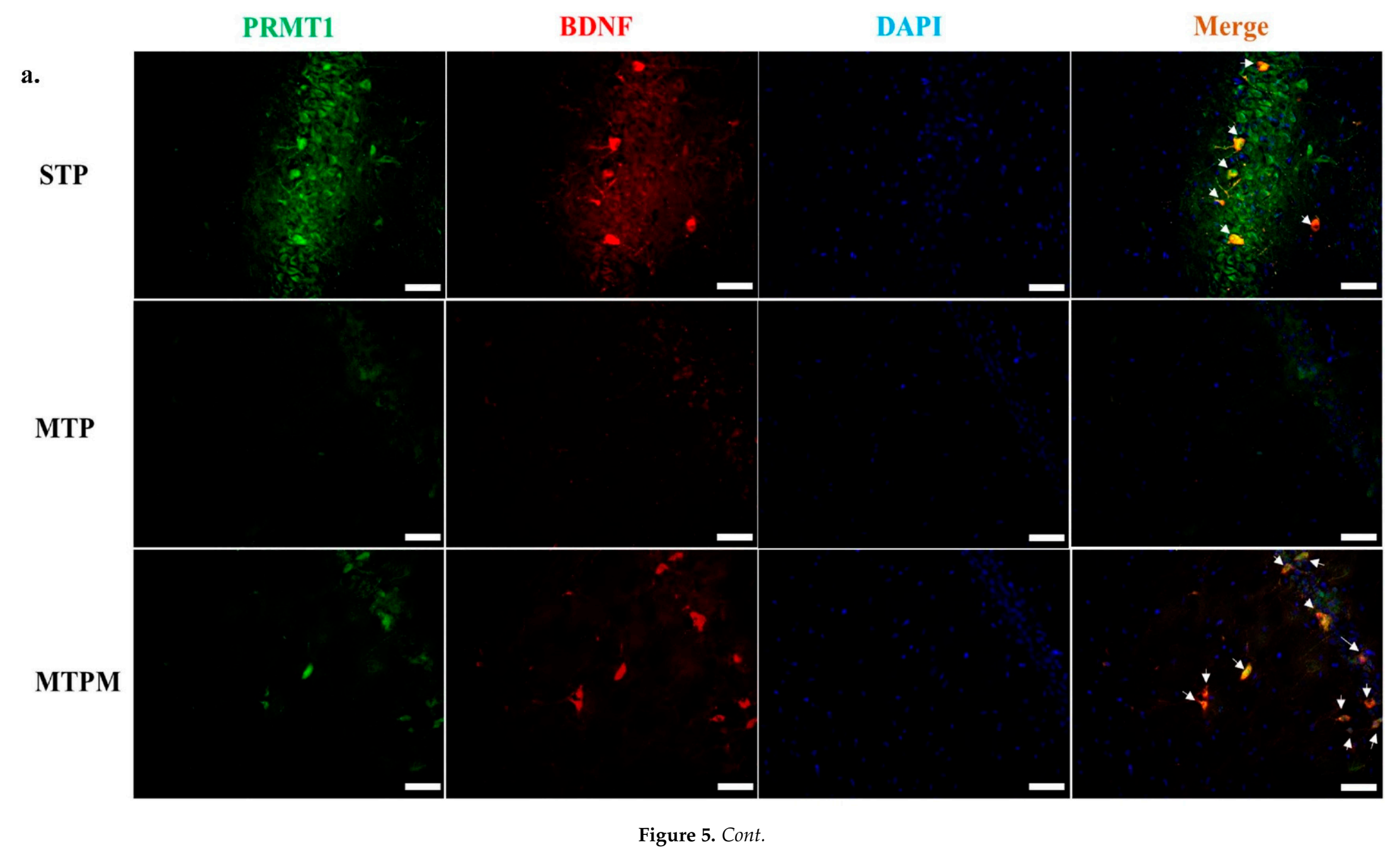




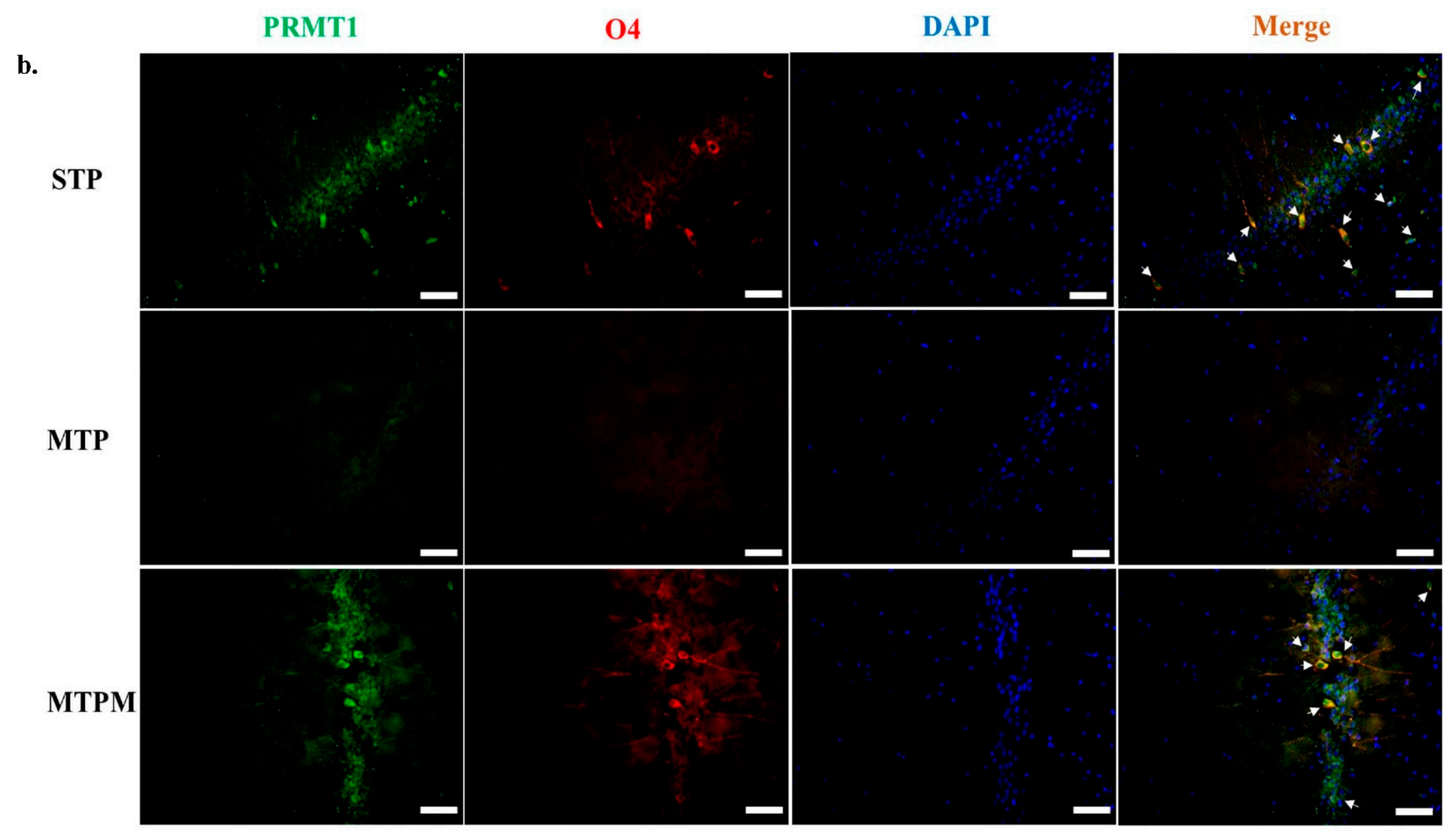

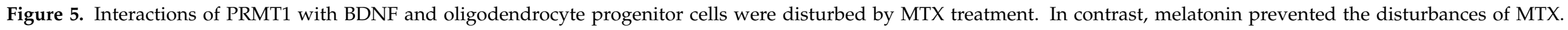

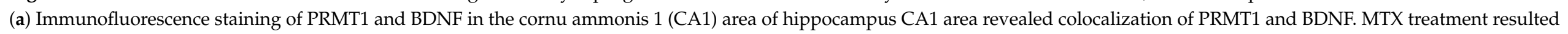

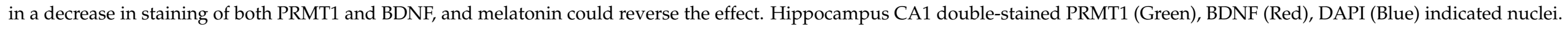

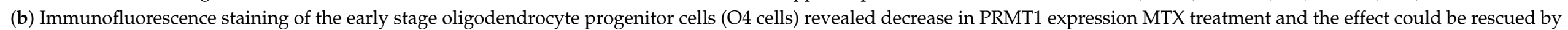

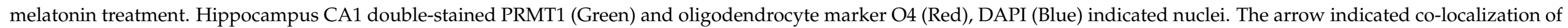
PRMT1/BDNF or PRMT1/O4 in CA1 area. Each bar indicated $50 \mu \mathrm{m}$. 
a.
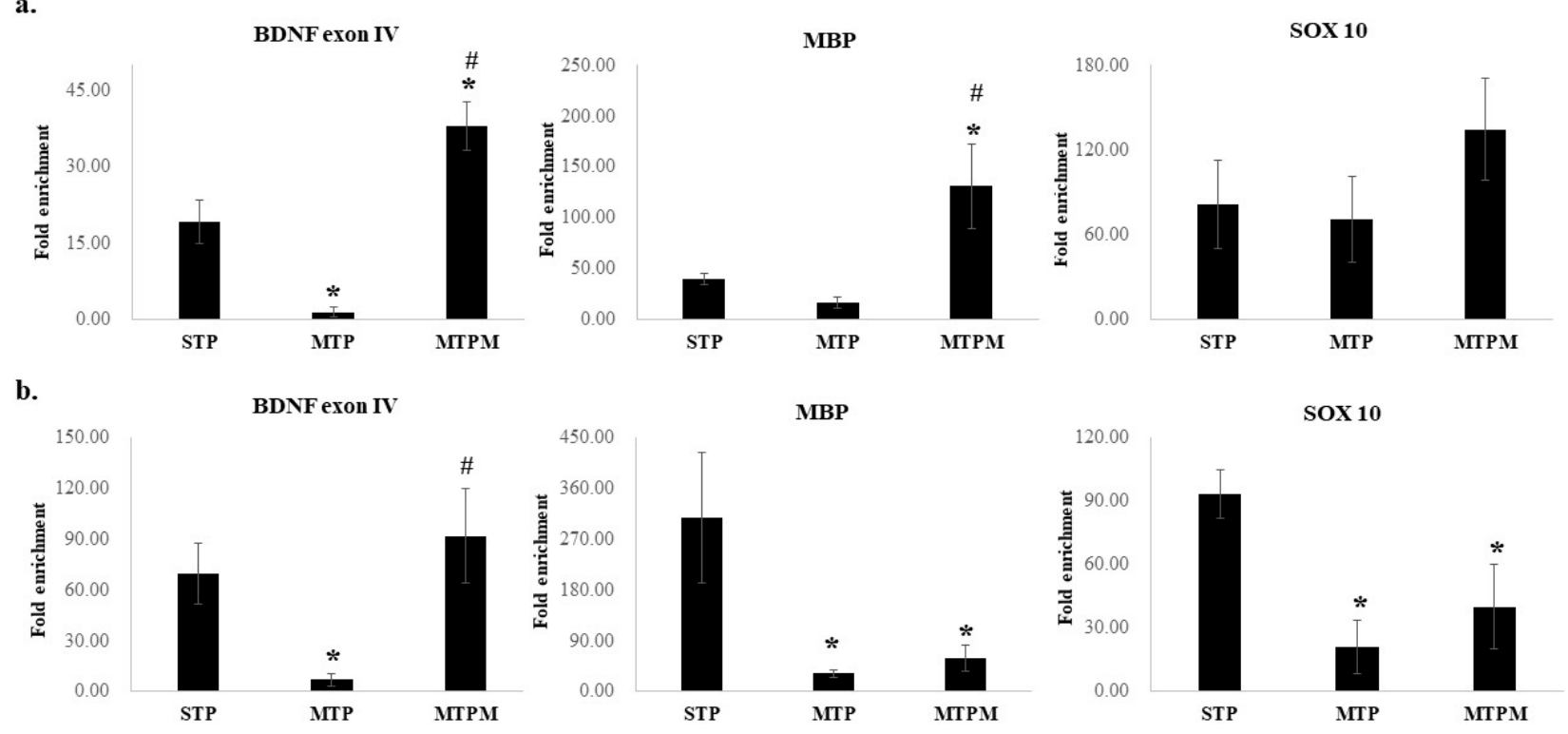

Figure 6. RPMT 1 regulated BDNF exon IV and myelination-related transcriptomes were repressed by MTX treatment while melatonin restored it. (a) RIP exam found significant decrease of BDNF exon IV and decrease of MBP and SOX 10 promoter in brain cortex. (b) RIP exam found significant decrease of BDNF exon IV, MBP, and SOX 10 in hippocampus. $\left({ }^{*} p<0.05\right.$ vs. STP; $\# p<0.05$ vs. MTP).

\section{Discussion}

Since we have demonstrated that combined IT and IP MTX treatment resulted in spatial memory deficits in developing rats, we conducted this study to uncover the underlying mechanisms, and the findings are summarized below. First, combined intrathecal and intraperitoneal methotrexate treatment resulted in both functional and epigenetic changes in the developing brain. Second, the hippocampus is more susceptible to MTX treatment, mostly due to epigenetic modifications. Third, the interaction of PRMT1 with the translational process (mRNA expression) by RIP in our study provides evidence that PRMT1 may be involved in the process of myelination dysregulation in MTX neurotoxicity. Fourth, our study provides a treatment option for MTX neuropathy using medications targeting the epigenetic pathway, possibly through H3R4me2a. Finally, melatonin rescues MTX neurotoxicity not only through its antioxidant effects, but also by modulating the epigenetic process.

Nowadays, improvement of cancer survival has been reported following integration of multiple treatment strategies. However, $\mathrm{CRCI}$ is still a hard task for cancer survivors and attracts much attention. Previously, it has been suggested that CRCI is a consequence of cytokine release following chemotherapy $[36,37]$. Recently, more and more studies claimed that not only the direct effect of chemotherapy or inflammation response induced by chemotherapy on the nervous system, but the impact of the chemotherapy on neuron plasticity and repair leads to the development of CRCI. Koh et al. has found that the role of cancer exosomes and their ability to interact with the nervous system is essential in modulating neurological processes such as neuronal functioning and stress response, which might also contribute to CRCI $[38,39]$. Similar to Koh's report, our work emphasizes the alteration of neuronal plasticity through the change in the myelination process contributes to CRCI. In addition, it deserves to note that despite growing studies work on the mechanism of CRCI, there was only one study to discuss the epigenetic impact on the development of CRCI [40]. To date, there are limited studies to discuss the impact of epigenetic programming and CRCI [40,41]. Wang et al. stated that chemobrain was related to the epigenetic reprogramming of the cancer patients and the cytokine response to the 
chemotherapy [41]. Unlike Wang's work, our study emphasizes the epigenetic changes on the myelination process following MTX treatment and is considered to be the first study to directly examine the brain myelination-related transcriptomes change after chemotherapy. Moreover, to investigate the $\mathrm{CRCI}$ from the view of exosome dynamics in the future would make the work more comprehensive.

Chemobrain by MTX was previously considered to be due to the dysregulation of oxidative stress. Gibson et al. examined the postmortem specimen after MTX chemotherapy and found persistent tri-glial dysfunction underlies MTX chemotherapy-related cognitive impairment [18]. Similar to our study, Gibson et al. used a mouse model mimicking leukemia treatment protocol to examine the effect of MTX exposure on juvenile rats and found microglial depletion, decreased astrocyte reactivity, altered oligodendroglial lineage dynamics [18]. Furthermore, Geraghty et al. demonstrated that loss of adaptive myelination contributes to MTX chemotherapy-related cognitive impairment through the evidence that microglial-dependent reduction of BDNF expression and loss of activity-regulated myelination [32]. Consistent with our findings, these results indicate that the dysregulation of the myelination process underlies the mechanism of chemobrain following MTX.

To date, only one study conducted by Forster et al. has investigated the role of MTX on DNA methylation in the pathogenetic process of MTX neurotoxicity [42]. However, Forster et al. studied the impact of MTX on epigenetic modification using normal neural cell lines and emphasized that depletion of S-adenosyl methionine had an impact on myelination [42]. In this study, we found that MTX treatment resulted in the alteration of epigenetic modifications of the neurotrophin gene and myelination-related proteins gene expression, while the concept that neurotoxicity following MTX treatment may be a result of the dysregulation of the epigenetic process in neurotrophin genes has rarely been reported. Moreover, we examined the neurotrophin and myelination-related proteins gene expression in brain cortex and hippocampus rather than cell lines. Therefore, we suggested that MTX neurotoxicity was not only a consequence of an imbalance in oxidative stress, but also due to a change in the epigenetic regulation of neurotrophin and myelinationrelated transcriptomes.

The impact of MTX treatment on the nervous system most commonly manifests as spatial memory impairment, which was considered to be due to its effect on the hippocampus. In this study, epigenetic changes after MTX treatment were mostly found in the hippocampus, with minimal effects on the brain cortex. This finding seems to be correlated with the results of brain morphology and functional study after MTX treatment. According to the literature, distribution of MTX after either intravenous or intraventricular injection is uneven [43-45]. Westerhout et al. demonstrated that the spatial distribution in CNS of unbound MTX after intraventricular administration was significantly related to the distance from the injection site. In addition, the balance between brain extracellular fluid status and cerebrospinal fluid (CSF) determined also the spatial distribution of MTX [45]. Furthermore, the diseased neuron and the healthy neuron had difference in susceptibility of MTX, thus the impact of MTX on the diseased neuron and the healthy neuron is different. To this end, we conclude that the hippocampus is more susceptible to MTX treatment in both functional and neurogenesis aspects, which might be explained by the higher MTX concentration in hippocampus than brain cortex. However, since we used healthy animals in the study, we suggested that the finding should be interpretated cautiously because the MTX concentration in the real patients is different from the health subjects.

Using the ChIP method, we found a significant decrease in the concentration of H4R3me2a and an increase in the concentration of MeCP2 in the hippocampus in the BDNF exon IV promoter region, which was successfully rescued by melatonin treatment by altering the concentrations of H4R3me2a in the brain cortex and hippocampus. In addition, significant changes in the concentrations of H4R3me2a, MeCP2, H3K36me3, and H3K4me3 in the SOX10 promoter region were noted after MTX treatment in the hippocampus, while the effect of MTX on the brain cortex was less significant. Further, studies on the concentrations of $\mathrm{H} 4 \mathrm{R} 3 \mathrm{me} 2 \mathrm{a}, \mathrm{MeCP} 2, \mathrm{H} 3 \mathrm{~K} 36 \mathrm{me} 3$, and $\mathrm{H} 3 \mathrm{~K} 4 \mathrm{me} 3$ in the MBP promoter 
region revealed significant alterations in the expression levels in the hippocampus compared with the brain cortex. Following melatonin treatment, the H4R3me2a concentrations seemed to be recovered in both the SOX 10 and MBP promoter regions in the hippocampus. Taken together, we found that MTX treatment modulated MBP and SOX10 expressions through the alteration of the H4R3me2a and MeCP2-binding affinities of the promoter regions in the hippocampus, and melatonin exerted its effect on epigenetic modification through H4R3me2a in the myelination proteins mostly in the hippocampus. To the best our knowledge, this is the first study to illustrate that melatonin may work through epigenetic modifications to rescue the effect of MTX on the CNS.

In our previous study, we found that PRMT1 expression was altered by combined IT and IP MTX treatment. Moreover, increasing evidence suggests that PRMT1 plays an essential role in post-translational modification through interaction with myelination-related transcriptomes. Therefore, we used substrate-enrichment methodologies to evaluate the role of PRMT1 in the post-translational modification of myelination-related transcriptomes. Using the RIP method, we found a significant decrease in BDNF exon IV in both the brain cortex and hippocampus, which can be successfully rescued by melatonin. In addition, there was a significant decrease in the expression levels of MBP and SOX 10 in the hippocampus. These findings suggest that PRMT1 plays an essential role in the posttranslational modification of BDNF, MBP, and SOX10, and the finding that the hippocampus was more deeply affected by MTX treatment was consistent with the formal studies.

Despite we have tried great effort to elucidate the mechanism of MTX neurotoxicity through epigenetic reprogramming on myelination process in the developing brain, several unsolved questions remain. First, since we have found that PRMT1 is involved in the myelination process in response to MTX treatment, the key substrates of PRMT1 regulation of neurogenesis and repair processes remain unclear. The antibody-based PRMT1 substrateenrichment strategy utilized may not have captured all substrates because PRMT1 also acts on substrates without typical arginine-glycine-rich motifs. Second, the interrelationship between PRMT1 and other PRMTs, in terms of the functional regulation of the brain after MTX treatment, was not explored in the present study. For a more comprehensive intervention of the role of PRMTs in the epigenetic modification of the genes of neurotrophin and myelination-related transcriptomes, further studies on other PRMTs are required. Third, since PRMT1 protein concentrations have been shown to gradually increase during brain development and become maintained in adult brains [34], PRMT1 has stage-dependent functions which may further change in a disease-related fashion. Fourth, differential spatial distribution of MTX in brain warrants further study to explain the different extent of involvement in epigenetic programming in cortex and hippocampus. Addressing these remaining questions, notably utilizing exosomes as means to explore different body compartments will lead to a further understanding of mechanism of MTX neurotoxicity.

\section{Material and Methods}

\subsection{Subjects}

This experiment was performed per the Guidelines for Animal Experiments of Chang Gung Memorial Hospital and Chang Gung University. The experiments were approved by the Institutional Animal Care and Use Committee, Taiwan (approval number: 2018032204; approval date: 2 May 2018). The day of delivery was defined as day 0. Male SpragueDawley rats (PND $17 \pm 1$ ) weighing $50 \mathrm{~g}$ were used. Attempts were made to minimize the number of animals used. All animals were housed in a room maintained at $24{ }^{\circ} \mathrm{C}$ a $12-\mathrm{h}$ light/dark cycle and had free access to standard chow.

According to Forsythe et al. higher incidence rates of childhood acute lymphoblastic leukemia was found in boys compared to girls [42]. Besides, since we used melatonin as the therapeutic agent, its anti-estrogen effect was ever reported [46,47]. Furthermore, this study was an extended research from our previous study [14], which used Morris water maze (MWM) to determine the neurobehavior changes and thus built up a male rats MWM database. Therefore, we choose male rats as our target subjects in this study. 


\subsection{Experimental Procedures}

All surgical procedures were performed under anesthesia with Zoletil50 $(25 \mathrm{mg} / \mathrm{kg})$ and xylazine $(23 \mathrm{mg} / \mathrm{kg})$, as previously described [48]. Each group of rats received an intrathecal injection via a transcutaneous cisternal magna puncture. Briefly, the rats were anesthetized and positioned in the lateral decubitus position. A 27-gauge needle was inserted into the cisterna magna. The correct position was verified by the outflow of CSF, and the polyethylene catheters were inserted through a small incision in the atlantooccipital membrane and passed $1.5 \mathrm{~cm}$ caudally to the level of the lumbar enlargement of the catheters [49]. To confirm the correct placement of the catheters, $10 \mu \mathrm{L}$ of $0.9 \%$ saline was flushed into them the day after surgery.

As we have already demonstrated that combined MTX-intrathecal and intraperitoneal treatment may result in significant spatial memory changes along with a marked decrease in brain-related protein expression and decreased myelination, we focused on the combined MTX-intrathecal and intraperitoneal groups in the present study. The dosages of MTX were selected based on our preliminary experiments and previous reports $[13,14,50]$.

There were three experimental groups in this project $(\mathrm{N}=10-14$, each).

1. Sham (STP): rats that underwent catheter implantation surgery received an equal volume of normal saline with MTX treatment via intrathecal injection (IT) and intraperitoneal injection (IP).

2. MTP: rats that underwent catheter implantation surgery received $0.5 \mathrm{mg} / \mathrm{kg}$ of methotrexate diluted with $0.9 \%$ normal saline in $5-10 \mu \mathrm{L}$ as the final volume via intrathecal injection once per week for two weeks. The rats received $100 \mathrm{mg} / \mathrm{kg}$ methotrexate via i.p. injection $24 \mathrm{~h}$ after each dose of IT injection.

3. MTPM: rats that received intraperitoneal melatonin treatment of $100 \mathrm{mg} / \mathrm{kg}$ of melatonin $1 \mathrm{~h}$ before methotrexate treatment (IT $+\mathrm{IP})$.

\section{Experimental paradigm of this study}

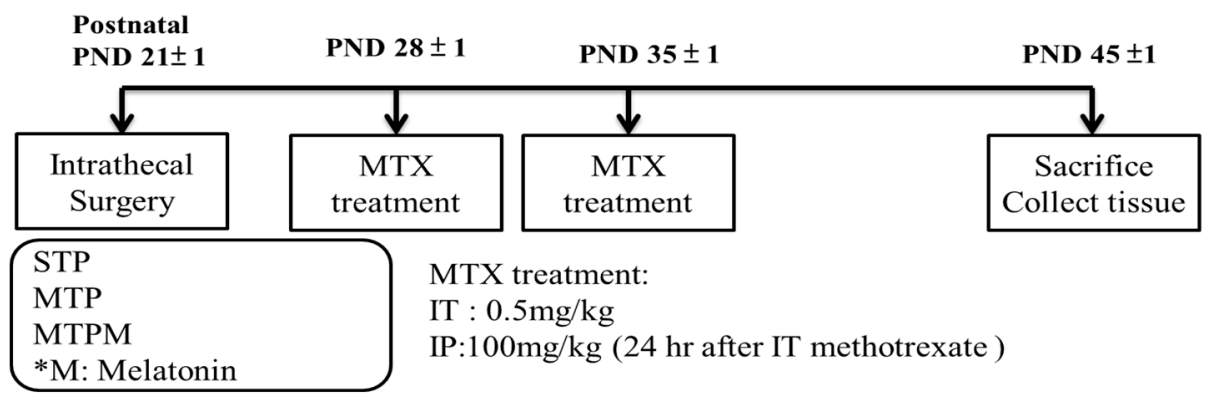

\subsection{Brain Tissue Collection}

The brain tissue was removed and homogenized immediately after the rats were sacrificed at PND 45. We examine two regions that are involved in spatial performance in rats: the prefrontal cortex and hippocampus [51,52]. The prefrontal cortex and hippocampus are removed immediately after rats are sacrificed, and tissues are homogenized. Before collection, all brain tissues were perfused with $0.9 \%$ iced saline. The hippocampus is primarily involved in cognition and spatial performance, thus we examined exclusively the hippocampus in the immunofluorescence staining [52,53].

\subsection{DNA Bisulfite Modification and Pyrosequencing}

According to a previous study, DNA from the prefrontal cortex or hippocampus tissue was used in the study, and genomic DNA extraction was performed using the tissue genomic DNA extraction mini kit (Favorgen Biotech Corp, Taipei, Taiwan) [54]. In brief, $500 \mathrm{ng}$ of genomic DNA was used for bisulfite modification (EZ DNA MethylationGold Kit, Zymo Research, Irvine, CA, USA). DNA methylation level quantitation analysis was conducted using pyrosequencing, as previously described. The gene promoter of 
interest was amplified from bisulfite-converted DNA by PCR. To isolate the single-stranded amplicon, the anti-sense primers used in PCR reactions were specially designed with a biotin moiety at the $5^{\prime}$ terminus. A total PCR reaction with a volume of $25 \mu \mathrm{L}$ was performed, which involved $2 \mu \mathrm{L}$ of the bisulfite-modified DNA template, PyroMark PCR Master Mix (Qiagen, Hilden, Germany), oral load concentrate, $25 \mathrm{mM} \mathrm{MgCl}$, and $10 \mu \mathrm{M}$ each of gene-specific forward and reverse primers. Thermocycling was conducted using the following general parameters: $95^{\circ} \mathrm{C}$ for $15 \mathrm{~min}$, followed by 50 cycles at $95^{\circ} \mathrm{C}$ for $30 \mathrm{~s}, 58-60$ ${ }^{\circ} \mathrm{C}$ for $30 \mathrm{~s}, 72{ }^{\circ} \mathrm{C}$ for $1 \mathrm{~min}$, and final extension at $72{ }^{\circ} \mathrm{C}$ for $10 \mathrm{~min}$. Following amplification, 10-20 $\mu \mathrm{L}$ of PCR product was mixed with streptavidin-conjugated sepharose beads (GE Healthcare, Boston, MA, USA) in a binding buffer (Qiagen, Germantown, MD, USA) and diluted to $80 \mu \mathrm{L}$ total volume with ddH2O. The beads were subsequently collected using a vacuum preparation workstation and sequencing primer and heated to $82{ }^{\circ} \mathrm{C}$ for $2 \mathrm{~min}$. The sequencing primers, shown in Table 1, were annealed to the biotinylated DNA strand as the reaction mixture was cooled to room temperature. Pyrosequencing was performed using a PyroMark Q24 system (Qiagen, Hilden, Germany). The peak heights of the CpG sites were calculated and converted into percentages of $\mathrm{C} / \mathrm{C}+\mathrm{T}$ representing methylation status using PyroMark Q24 Advanced software (version: 3.0.0; Build: 21).

Table 1. Primer set for pyrosequencing.

\begin{tabular}{|c|c|c|c|}
\hline Gene & Forward $\left(5^{\prime}-3^{\prime}\right)$ & Reverse $\left(5^{\prime}-3^{\prime}\right)$ Biotinylated & Sequencing Primer \\
\hline$B D N F$ exon & AGGTAGAGGAGGTATTATATGATAGT & ACTATATATTТССССТТСТСТТСААТT & AGGAGGTATTATATGATAGTT \\
\hline IV & AGGTAGAGGAGGTATTATATGATAGT & ААСТСТТАСТАТАТАТТТССССТТСТ & ATTTATAGAGGAGAGGATTGT \\
\hline MBP & GAGATAGTTAGTTTAAGATTTTAGGAAGAA & ACССТАССАAТTATTСТTТАAАТСТАСТ & GTTAGTTTAAGATTTTAGGAAGAAA \\
\hline SOX10 & GTTAGGTAAGGTAGATTTTAAAAGGGATG & TAACСАCAАCСАAАACACТАСТСАА & $\begin{array}{l}\text { GTAGATTTTAAAAGGGATGG } \\
\text { ATGTGATTGAGTTGGAT }\end{array}$ \\
\hline
\end{tabular}

\subsection{Chromatin Immunoprecipitation (ChIP) Assay for BDNF and Myelination-Related Transcriptomes Modification}

Chromatin immunoprecipitation was performed as previously described using the Magna ChIP ${ }^{\mathrm{TM}}$ A/G Chromatin Immunoprecipitation Kit (Millipore, Billerica, MA, USA) according to the manufacturer's instructions [36,55-57]. Sheared chromatin $(90 \mu \mathrm{L})$ from the prefrontal cortex or hippocampus was used for immunoprecipitation and incubated at $4{ }^{\circ} \mathrm{C}$ overnight with primary antibodies (anti-H4R3me2a, anti-H3K4me3, antiH3K36me3, and anti-MeCP2; Abcam, Cambridge, UK) or normal rabbit IgG (negative control, supplied in the kit). Meanwhile, $5 \mu \mathrm{L}$ of sheared chromatin was saved as input for normalization. Follow-up purified gDNA from each antibody was used at the BDNF exon IV, MBP, and SOX10 promoter region via real-time PCR (Table 2). The percentage input was calculated using the following formula: $\Delta \mathrm{Ct}$ [normalized $\mathrm{ChIP}]=(\mathrm{Ct}[\mathrm{ChIP}]-(\mathrm{Ct}$ [Input] - Log2 (Input dilution factor), where dilution factor $=5 / 90=18.5$. Finally, input $\%=100 / 2^{\Delta \mathrm{Ct}}[$ normalized ChIP] , with this value delegating the enrichment of epigenetic modifications in specific regions.

Table 2. Primer set for ChIP assay.

\begin{tabular}{|c|c|c|}
\hline & Forward $5^{\prime}-3^{\prime}$ & Reverse $5^{\prime}-3^{\prime}$ \\
\hline BDNF exon IV promoter & TGACAGCTCACGTCAAGGCA & ATCTAGGCAGAGACTGGGAGAT \\
\hline MBP promoter & AGCTAGTTCAAGACCCCAGG & AGATATGAATGTGGGCCTGTGC \\
\hline SOX10 promoter & CAGCCATGAGGTAATGTCCA & GTAGCCAGCTGCCGAGTAG \\
\hline
\end{tabular}

\subsection{RNA-Protein Immunoprecipitation (RIP) Assay}

RIP was performed using an EZ-Magna RIP Kit (Millipore, Billerica, MA, USA) according to the manufacturer's instructions. Cells were lysed using a complete RNA lysis buffer with protease inhibitor and RNase. Total of $100 \mu \mathrm{L}$ of cell lysate was incubated with RIP buffer containing magnetic beads conjugated with antibodies of PRMT1 (1:80X) or 
with negative control (IgG), and $10 \mu \mathrm{L}$ of cell lysate was used as the input in the following procedure. Wash buffer was added to all RIP reactions and vortexed gently, and the wash steps were repeated until the magnetic beads were washed five times. Thus, purified RNAs from different immunoprecipitated antibodies were transcribed into cDNA and analyzed for BDNF exon IV, MBP, and SOX10 mRNA expression levels via real-time PCR. The values were calculated as fold enrichment $=2^{(\Delta \mathrm{Ct}(\mathrm{IP})-\Delta \mathrm{Ct}(\text { mock }))}$.

\subsection{Quantitative Real-Time PCR Analysis}

PCR analysis was performed as previously reported [48]. The parameters examined included BDNF exon IV, MBP, and SOX10 (Table 3).

Table 3. Pirmer design for real-time PCR.

\begin{tabular}{ccc}
\hline & \multicolumn{1}{c}{ Forward $\mathbf{5}^{\prime} \mathbf{- 3}^{\prime}$} & Reverse $^{\mathbf{\prime}} \mathbf{- 3}^{\prime}$ \\
\hline BDNF exon IV & ATTCACCGAGGAGAGGACTG & AGTCTTTGGTGGCCGATATG \\
MBP & CTCTGGCAAGG CTCACACAC & TCTGCTGAGGGACAGGCCTCTC \\
SOX10 & TACAAGTACCAACCTCGGCG & CATGGGGGAGCCTTCTTCTG \\
\hline
\end{tabular}

\subsection{Immunofluorescence Staining}

Cryosections of brain tissue were cut in a facial orientation of $16 \mu \mathrm{m}$ thickness and used in the following procedures, as previously described (14). Anti-PRMT1 antibody (Rabbit; Abcam, Cambridge, UK), anti-BDNF (Mouse; Proteintech, IL, USA), and antioligodendrocyte marker 4 (O4, Mouse; STEMCELL Technologies Inc., Vancouver, BC, Canada) antibody were diluted in ratios of 1:100, 1:100, and 1:50 in phosphate buffer saline (PBS, pH 7.4) and incubated overnight at $4{ }^{\circ} \mathrm{C}$. Specific protein distributions in the hippocampus were detected using Alexa Fluor-594 at a 1:100 ratio (Thermo Fisher, Waltham, MA, USA), conjugated with anti-mouse antibody and Alexa Fluor-488 at a 1:500 ratio (Thermo Fisher, Waltham, MA, USA), and conjugated with anti-rabbit antibody. Finally, the slices were mounted and imaged using a microscope (Olympus, Tokyo, Japan).

\subsection{Statistical Analysis}

$\mathrm{PCR}$, pyrosequencing, and ChIP were analyzed using one-way ANOVA with an LSD post-hoc test. All analyses were performed using SPSS on a PC-compatible computer. The values are expressed as mean \pm SEM, and significance was set at $p<0.05$ for all tests.

\section{Conclusions}

In conclusion, the study indicated that an epigenetic process underlies the pathogenesis of MTX neurotoxicity, mainly in the neurogenesis and myelination processes. Furthermore, this is the first study to address the interaction between PRMT1 and neurotrophin and myelination-related transcriptomes in post-translational regulation.

Author Contributions: Conceptualization, Y.-C.C. and J.-M.S.; methodology, L.-T.H.; software, S.C.W.; validation, Y.-C.C., M.-H.H. and L.-T.H.; formal analysis, C.-C.H.; investigation, K.-A.C.; resources, J.-M.S.; data curation, S.-C.W.; writing — original draft preparation, Y.-C.C.; writing—review and editing, L.-T.H.; visualization, M.-H.H.; supervision, L.-T.H.; project administration, Y.-C.C. All authors have read and agreed to the published version of the manuscript.

Funding: This work was supported by grants CMRPG8H0611 and CMRPG8H0612 from Kaohsiung Chang Gung Memorial Hospital, Taiwan.

Conflicts of Interest: The authors declare no conflict of interest. 


\section{References}

1. Cascella, M.; Napoli, D.R.; Carbone, D.; Cuomo, G.F.; Bimonte, S.; Muzio, M.R. Chemotherapy-related cognitive impairment: Mechanisms, clinical features and research perspectives. Recent. Prog. Med. 2018, 109, 523-530.

2. Torrente, N.C.; Navarro Pastor, J.B.; dela Osa Chaparro, N. Systematic review of cognitive sequelae of non-central nervous system cancer and cancer therapy. J. Cancer Surviv. 2020, 14, 464-482. [CrossRef] [PubMed]

3. Pui, C.H.; Campana, D.; Pei, D.; Bowman, W.P.; Sandlund, J.T.; Kaste, S.C.; Ribeiro, R.C.; Rubnitz, J.E.; Raimondi, S.C.; Onciu, M.; et al. Treating childhood acute lymphoblastic leukemia without cranial irradiation. N. Engl. J. Med. 2009, 360, $2730-2741$. [CrossRef] [PubMed]

4. Pui, C.H.; Mullighan, C.G.; Evans, W.E.; Relling, M.V. Pediatric acute lymphoblastic leukemia: Where are we going and how do we get there? Blood 2012, 120, 1165-1174. [CrossRef] [PubMed]

5. Pui, C.H.; Yang, J.J.; Hunger, S.P.; Pieters, R.; Schrappe, M.; Biondi, A.; Vora, A.; Baruchel, A.; Silverman, L.B.; Schmiegelow, K.; et al. Childhood acute lymphoblastic leukemia: Progress through collaboration. J. Clin. Oncol. 2015, 33, 2938-2948. [CrossRef]

6. Iyer, N.S.; Balsamo, L.M.; Bracken, M.B.; Kadan-Lottick, N.S. Chemotherapy-only treatment effects on long-term neurocognitive functioning in childhood ALL survivors: A review and meta-analysis. Blood 2015, 126, 346-353. [CrossRef] [PubMed]

7. Millan, N.C.; Pastrana, A.; Guitter, M.R.; Zubizarreta, P.A.; Monges, M.S.; Felice, M.S. Acute and sub-acute neurological toxicity in children treated for acute lymphoblastic leukemia. Leuk. Res. 2018, 65, 86-93. [CrossRef]

8. Cheung, Y.T.; Krull, K.R. Neurocognitive outcomes in long-term survivors of childhood acute lymphoblastic leukemia treated on contemporary treatment protocols: A systematic review. Neurosci. Biobehav. Rev. 2015, 53, 108-120. [CrossRef]

9. Moe, P.J.; Holen, A. High-dose methotrexate in childhood all. Pediatr. Hematol. Oncol. 2000, 17, 615-622. [CrossRef]

10. Cohen, I.J. Neurotoxicity after high-dose methotrexate (MTX) is adequately explained by insufficient folinic acid rescue. Cancer Chemother. Pharmacol. 2017, 79, 1057-1065. [CrossRef]

11. Vezmar, S.; Schüsseler, P.; Becker, A.; Bode, U.; Jaehde, U. Methotrexate-associated alterations of the folate and methyl-transfer pathway in the CSF of All patients with and without symptoms of neurotoxicity. Pediatr. Blood Cancer 2009, 52, 26-32. [CrossRef] [PubMed]

12. Sirichoat, A.; Krutsri, S.; Suwannakot, K.; Aranarochana, A.; Chaisawang, P.; Pannangrong, W.; Wigmore, P.; Welbat, J.U. Melatonin protects against methotrexate-induced memory deficit and hippocampal neurogenesis impairment in a rat model. Biochem. Pharmacol. 2019, 163, 225-233. [CrossRef] [PubMed]

13. Wen, J.; Maxwell, R.R.; Wolf, A.J.; Spira, M.; Gulinello, M.E.; Cole, P.D. Methotrexate causes persistent deficits in memory and executive function in a juvenile animal model. Neuropharmacology 2018, 139, 76-84. [CrossRef]

14. Chen, Y.C.; Sheen, J.M.; Hsu, M.H.; Hsiao, C.C.; Wang, S.C.; Huang, L.T. Melatonin rescued methotrexate-induced spatial deficit and hyperhomocysteinemia and increased asymmetric dimethylarginine in plasma and dorsal hippocampus in developing rats. Life Sci. 2020, 242, 116931. [CrossRef] [PubMed]

15. Aukema, E.J.; Caan, M.W.A.; Oudhuis, N.; Majoie, C.B.L.M.; Vos, F.M.; Reneman, L.; Last, B.F.; Grootenhuis, M.A.; Schouten-van Meeteren, A.Y.N. White matter fractional anisotropy correlates with speed of processing and motor speed in young childhood cancer survivors. Int. J. Radiat. Oncol. Biol. Phys. 2009, 74, 837-843. [CrossRef]

16. Kaiser, J.; Bledowski, C.; Dietrich, J. Neural correlates of chemotherapy-related cognitive impairment. Cortex 2014, 54, 33-50. [CrossRef]

17. Pierson, C.; Waite, E.; Pyykkonen, B. A meta-analysis of the neuropsychological effects of chemotherapy in the treatment of childhood cancer. Pediatr. Blood Cancer 2016, 63, 1998-2003. [CrossRef]

18. Gibson, E.M.; Nagaraja, S.; Ocampo, A.; Tam, L.T.; Wood, L.S.; Pallegar, P.N.; Greene, J.J.; Geraghty, A.C.; Goldstein, A.K.; Ni, L.; et al. Methotrexate chemotherapy induces persistent tri-glial dysregulation that underlies chemotherapy-related cognitive impairment. Cell 2019, 176, 43-55. [CrossRef]

19. Kolli, V.K.; Abraham, P.; Isaac, B.; Kasthuri, N. Preclinical efficacy of melatonin to reduce methotrexate-induced oxidative stress and small intestinal damage in rats. Dig. Dis. Sci. 2013, 58, 959-969. [CrossRef]

20. Abraham, P.; Kolli, V.K.; Rabi, S. Melatonin attenuates methotrexate-induced oxidative stress and renal damage in rats. Cell Biochem. Funct. 2010, 28, 426-433. [CrossRef]

21. Oguz, E.; Kocarslan, S.; Tabur, S.; Sezen, H.; Yilmaz, Z.; Aksoy, N. Effects of lycopene alone or combined with melatonin on methotrexate-induced nephrotoxicity in rats. Asian Pac. J. Cancer Prev. 2015, 16, 6061-6066. [CrossRef]

22. Wegner, M. All purpose sox: The many roles of sox proteins in gene expression. Int. J. Biochem. Cell Biol. 2010, 42, 381-390. [CrossRef] [PubMed]

23. Weider, M.; Wegner, M. SoxE factors: Transcriptional regulators of neural differentiation and nervous system development. Semin Cell Dev. Biol. 2017, 63, 35-42. [CrossRef] [PubMed]

24. Weider, M.; Reiprich, S.; Wegner, M. Sox appeal-Sox10 attracts epigenetic and transcriptional regulators in myelinating glia. Biol. Chem. 2013, 394, 1583-1593. [CrossRef]

25. Fogarty, E.A.; Kitzman, J.O.; Antonellis, A. SOX10-regulated promoter use defines isoform-specific gene expression in Schwann cells. BMC Genom. 2020, 21, 549. [CrossRef]

26. Saur, A.L.; Fröb, F.; Weider, M.; Wegner, M. Formation of the node of Ranvier by Schwann cells is under control of transcription factor Sox10. Glia 2021, 69, 1464-1477. [CrossRef] 
27. Frazzini, V.; Granzotto, A.; Bomba, M.; Massetti, N.; Castelli, V.; d'Aurora, M.; Punzi, M.; Iorio, M.; Mosca, A.; Delli Pizzi, S.; et al. The pharmacological perturbation of brain zinc impairs BDNF-related signaling and the cognitive performances of young mice. Sci. Rep. 2018, 8, 9768. [CrossRef]

28. Kowiański, P.; Lietzau, G.; Czuba, E.; Waśkow, M.; Steliga, A.; Moryś, J. BDNF: A key factor with multipotent impact on brain signaling and synaptic plasticity. Cell Mol. Neurobiol. 2018, 38, 579-593. [CrossRef]

29. Fletcher, J.L.; Murray, S.S.; Xiao, J. Brain-derived neurotrophic factor in central nervous system myelination: A new mechanism to promote myelin plasticity and repair. Int. J. Mol. Sci. 2018, 19, 4131. [CrossRef] [PubMed]

30. Ng, T.; Lee, Y.Y.; Chae, J.W.; Yeo, A.H.L.; Shwe, M.; Gan, Y.X.; Ng, R.C.H.; Chu, P.P.Y.; Khor, C.C.; Ho, H.K.; et al. Evaluation of plasma brain-derived neurotrophic factor levels and self-perceived cognitive impairment post-chemotherapy: A longitudinal study. BMC Cancer 2017, 17, 867. [CrossRef] [PubMed]

31. Azoulay, D.; Leibovici, A.; Sharoni, R.; Shaoul, E.; Gross, B.; Braester, A.; Goldberg, H. Association between Met-BDNF allele and vulnerability to paclitaxel-induced peripheral neuropathy. Breast Cancer Res. Treat. 2015, 153, 703-704. [CrossRef]

32. Geraghty, A.C.; Gibson, E.M.; Ghanem, R.A.; Greene, J.J.; Ocampo, A.; Goldstein, A.K.; Ni, L.; Yang, T.; Marton, R.M.; Paşca, S.P.; et al. Loss of adaptive myelination contributes to methotrexate chemotherapy-related cognitive impairment. Neuron 2019, 103, 250-265. [CrossRef]

33. Hashimoto, M.; Fukamizu, A.; Nakagawa, T.; Kizuka, Y. Roles of protein arginine methyltransferase 1 (PRMT1) in brain development and disease. Biochim. Biophys. Acta Gen. Subj. 2021, 1865, 129776. [CrossRef] [PubMed]

34. Hashimoto, M.; Kumabe, A.; Kim, J.D.; Murata, K.; Sekizar, S.; Williams, A.; Lu, W.; Ishida, J.; Nakagawa, T.; Endo, M.; et al. Loss of PRMT1 in the central nervous system (CNS) induces reactive astrocytes and microglia during postnatal brain development. J. Neurochem. 2021, 156, 834-847. [CrossRef] [PubMed]

35. Forster, V.J.; McDonnell, A.; Theobald, R.; Mckay, J.A. Effect of methotrexate/vitamin B12 on DNA methylation as a potential factor in leukemia treatment-related neurotoxicity. Epigenomics 2017, 9, 1205-1218. [CrossRef] [PubMed]

36. Ren, X.; Keeney, J.T.R.; Miriyala, S.; Noel, T.; Powell, D.K.; Chaiswing, L.; Bondada, S.; St Clair, D.K.; Butterfield, D.A. The triangle of death of neurons: Oxidative damage, mitochondrial dysfunction, and loss of choline-containing biomolecules in brains of mice treated with doxorubicin. Advanced insights into mechanisms of chemotherapy induced cognitive impairment ("chemobrain") involving TNF- $\alpha$. Free Radic. Biol. Med. 2019, 134, 1-8. [PubMed]

37. Du, J.; Zhang, A.; Li, J.; Liu, X.; Wu, H.; Wang, B.; Wang, Y.; Jia, H. Doxorubicin-induced cognitive impairment: The mechanistic insights. Front. Oncol. 2021, 11, 673340. [CrossRef]

38. Koh, Y.Q.; Tan, C.J.; Toh, Y.L.; Sze, S.K.; Ho, H.K.; Limoli, C.L.; Chan, A. role of exosomes in cancer-elated cognitive impairment. Int. J. Mol. Sci. 2020, 21, 2755. [CrossRef]

39. Koh, Y.Q.; Ng, D.Q.; Ng, C.C.; Boey, A.; Wei, M.; Sze, S.K.; Ho, H.K.; Acharya, M.; Limoli, C.L.; Chan, A. Extracellular vesicle proteome of breast cancer patients with and without cognitive impairment following anthracycline-based chemotherapy: An exploratory study. Biomark. Insights 2021, 16, 1-12. [CrossRef]

40. Lyon, D.; Elmore, L.; Aboalela, N.; Merrill-Schools, J.; McCain, N.; Starkweather, A.; Elswick, R.K., Jr.; Jackson-Cook, C. Potential epigenetic mechanism(s) associated with the persistence of psychoneurological symptoms in women receiving chemotherapy for breast cancer: A hypothesis. Biol. Res. Nurs. 2014, 16, 160-174. [CrossRef]

41. Wang, X.M.; Walitt, B.; Saligan, L.; Tiwari, A.F.W.; Cheung, C.W.; Zhang, Z.-J. Chemobrain: A critical review and causal hypothesis of link between cytokines and epigenetic reprogramming associated with chemotherapy. Cytokine 2015, 72, 86-96. [CrossRef] [PubMed]

42. Forsythe, A.; Breland, T.; Majumdar, S.; Elkin, T.D.; Johnson, D.; Megason, G. Gender differences in incidence rates of childhood. B-precursor acute lymphocytic leukemia in Mississippi. J. Pediatr. Oncol. Nurs. 2010, 27, 164-167. [CrossRef] [PubMed]

43. Anderson, L.L.; Collins, G.J.; Ojima, Y.; Sullivan, R.D. A study of distribution of methotrexate in human tissues and tumors. Cancer Res. 1970, 30, 1344-1348. [PubMed]

44. Balis, F.M.; Blaney, S.M.; McCully, C.L.; Bacher, J.D.; Murphy, R.F.; Poplack, D.G. Methotrexate distribution within the subarachnoid space after intraventricular and intravenous administration. Cancer Chemother. Pharmacol. 2000, 45, 259-264. [CrossRef]

45. Westerhout, J.; van den Berg, D.-J.; Hartman, R.; Danhof, M.; de Lange, E.C.M. Prediction of methotrexate CNS distribution in different species-influence of disease conditions. Eur. J. Pharm. Sci. 2014, 16, 11-24. [CrossRef]

46. del Río, B.; García Pedrero, J.M.; Martínez-Campa, C.; Zuazua, P.; Lazo, P.S.; Ramos, S. Melatonin, an endogenous-specific inhibitor of estrogen receptor alpha via calmodulin. J. Biol. Chem. 2004, 279, 38294-38302. [CrossRef]

47. Cos, S.; González, A.; Martínez-Campa, C.; Mediavilla, M.D.; Alonso-González, C.; Sánchez-Barceló, E.J. Melatonin as a selective estrogen enzyme modulator. Curr. Cancer Drug Targets 2008, 8, 691-702. [CrossRef]

48. Huang, L.T.; Chen, C.C.; Sheen, J.M.; Chen, Y.J.; Hsieh, C.S.; Tain, Y.L. The interaction between high ammonia diet and bileduct ligation in developing rats: Assessment by spatial memory and asymmetric dimethylarginine. Int. J. Dev. Neurosci. 2010, 28, 169-174. [CrossRef]

49. Sheen, J.M.; Chen, Y.C.; Hsu, M.H.; Tain, Y.L.; Yu, H.R.; Huang, L.T. Combined intraperitoneal and intrathecal etanercept reduce increased brain tumor necrosis factor-alpha and asymmetric dimethylarginine levels and rescues spatial deficits in young rats after bile duct ligation. Front. Cell Neurosci. 2016, 10, 167. [CrossRef]

50. Cole, P.D.; Vijayanathan, V.; Ali, N.F.; Wagshul, M.E.; Tanenbaum, E.J.; Price, J.; Dalal, V.; Gulinello, M.E. Memantine protects rats treated with intrathecal methotrexate from developing spatial memory deficits. Clin. Cancer Res. 2013, 19, 4446-4454. [CrossRef] 
51. Dietrich, J.; Prust, M.; Kaiser, J. Chemotherapy, cognitive impairment and hippocampal toxicity. Neuroscience 2015, 309, 224-232. [CrossRef]

52. Sloan, H.L.; Good, M.; Dunnett, S.B. Double dissociation between hippocampal and prefrontal lesions on an operant delayed matching task and a water maze reference memory task. Behav. Brain Res. 2006, 171, 116-126. [CrossRef]

53. Parrish, R.R.; Buckingham, S.C.; Mascia, K.L.; Johnson, J.J.; Matyjasik, M.M.; Lockhart, R.M.; Lubin, F.D. Methionine increases BDNF DNA methylation and improves memory in epilepsy. Ann. Clin. Transl. Neurol. 2015, 2, 401-416. [CrossRef] [PubMed]

54. Demircan, B.; Dyer, L.M.; Gerace, M.; Lobenhofer, E.K.; Robertson, K.D.; Brown, K.D. Comparative epigenomics of human and mouse mammary tumors. Genes Chromosomes Cancer 2009, 48, 83-97. [CrossRef]

55. Lubin, F.D.; Roth, T.L.; Sweatt, J.D. Epigenetic regulation of BDNF gene transcription in the consolidation of fear memory. J. Neurosci. 2008, 28, 10576-10586. [CrossRef] [PubMed]

56. Liu, D.Y.; Shen, X.M.; Yuan, F.F.; Guo, O.Y.; Zhong, Y.; Chen, J.G.; Zhu, L.Q.; Wu, J. The physiology of BDNF and its relationship with ADHD. Mol. Neurobiol. 2015, 52, 1467-1476. [CrossRef] [PubMed]

57. Su, R.; Ma, J.; Zheng, J.; Liu, X.; Liu, Y.; Ruan, X.; Shen, S.; Yang, C.; Wang, D.; Cai, H.; et al. PABPC1-induced stabilization of BDNF-AS inhibits malignant progression of glioblastoma cells through STAU1-mediated decay. Cell Death Dis. 2020, 11, 81. [CrossRef] 